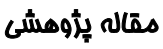

\section{بررسى بيماريهاى مرتبط با كار در كاركنان يكى از بيمارستانهاى شهر تهران}

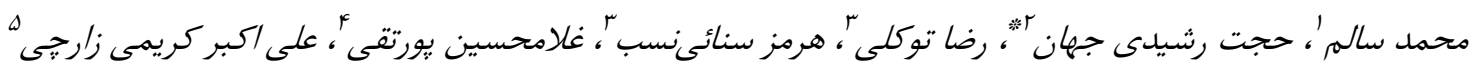

\author{
'مربى گروه مهندسى بهداشت حرفه اى، دانشكده بهداشت، دانشكاه علوم يزشكى بقيه ا...(عج)، تهران، ايران

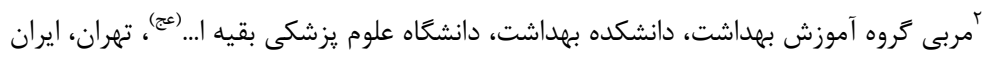

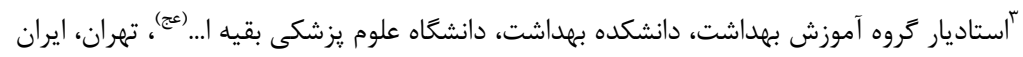

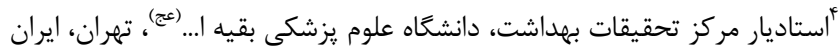

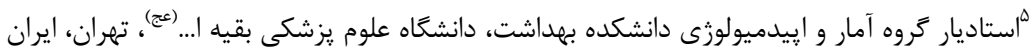

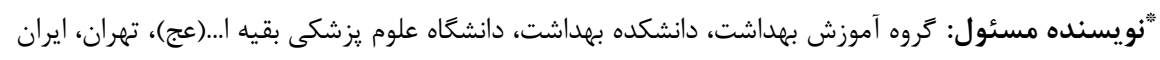

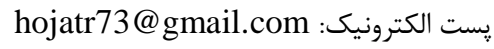

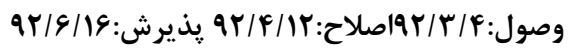

جكبيده

زمينه و هدف: با كسترش تكنولوزى و به علت در معرض قرار كرفتن برسنل شاغل با عوامل زيان آور مختلف فيزيكى، شيميايى،

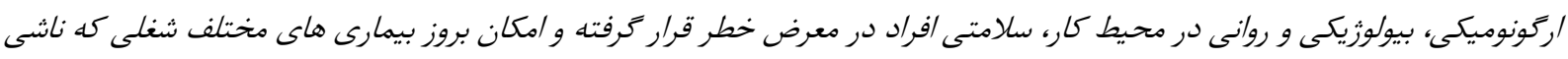

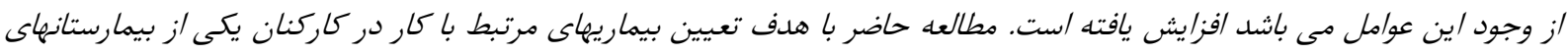

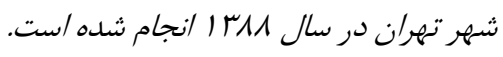

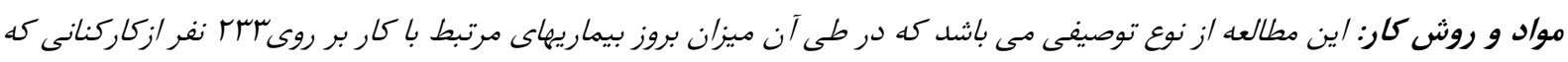
بيمارستان شهر تهران مورد مطالعه قرار كرفت.

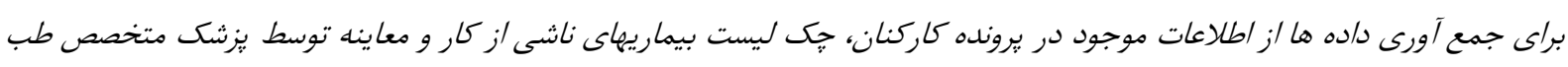

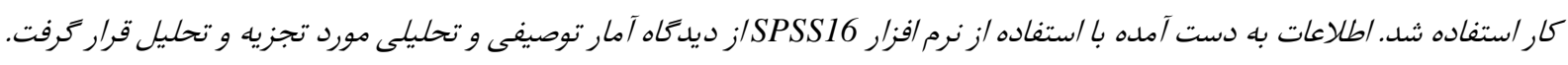

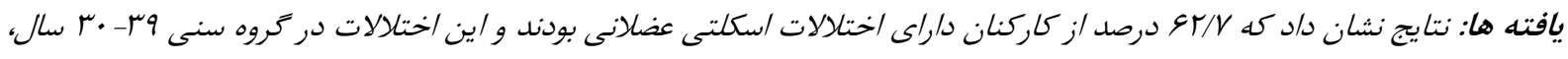

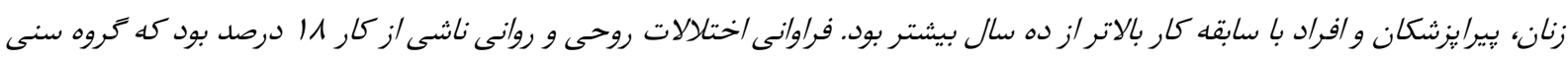

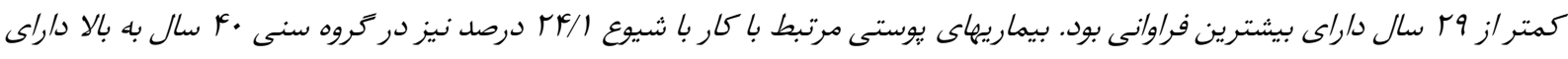

بيثترين فراوانى بود. نتيجه كيرى: با توجه به بالا بودن فراوانى بيماريهاى مرتبط با كار به ويزه اختلات /سكلتى عضلانى كه ناشى /ز سنكينى كار و عدم رعايت

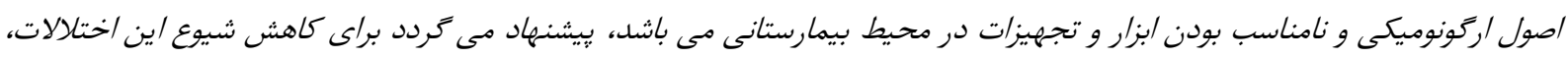
مداخلات آموزشى و بهسازى محيط متناسب با نوع فعاليت كاركنان انجام شود.

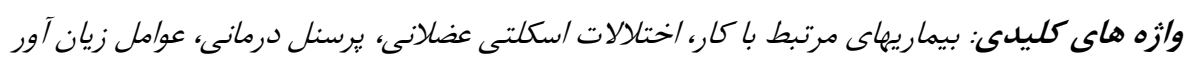

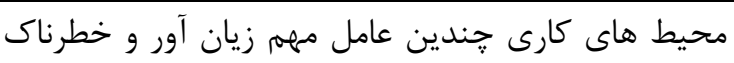
مقدمه

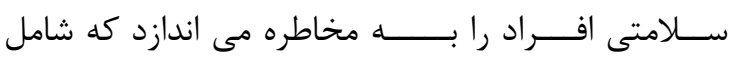
عوامل زيان آور فيزيكى، شيميايى، ارگونوميكى، بيولوزيكى إنى

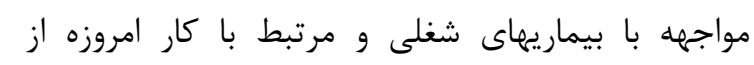

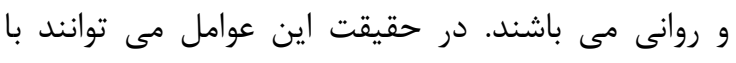

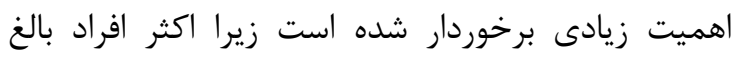
تاثير بر روى سلامتى شاغلين باعث ايجاد بيمارى و ناتوانى رئى داسنى

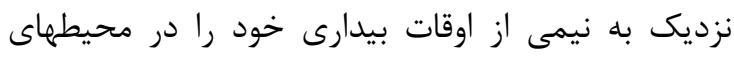

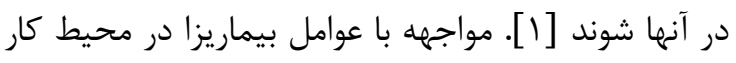
كارى مى حذرانند و در نتيجه تحت تاثير عوامل مختلفى كه در محيط كارشان وجود دارد قرار مى گيرند. در كليه 
استفاده از انواع شوينده ها ضد عفونى كننده ها و دستكشهاى لاتكس بوده است. عوامل مختلفى از جمله شغل و استرس هاى شغلى، جنسيت، وضعيت فيزيكى بدن، نحوه انجام فعاليت هاى روزانه در ايجاد دردهاى مفصلى با منشاء فيزيكى موثر مى نى ني باشند. بى توجهى به فشارهاى كارى و استرسهاى موجود در يرسنل واحدهاى درمانى مى تواند تبعات و هزينه هاى باى

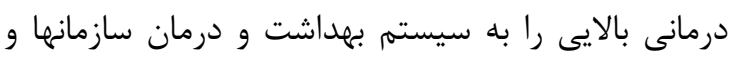

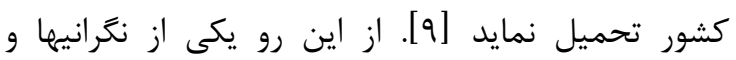

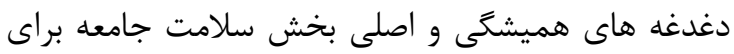

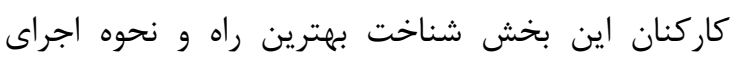

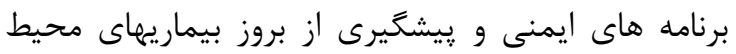

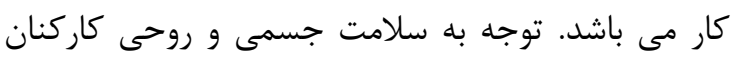

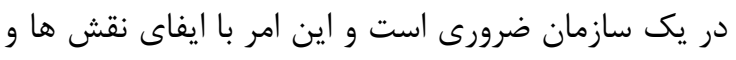

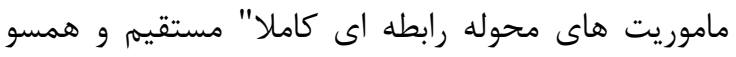

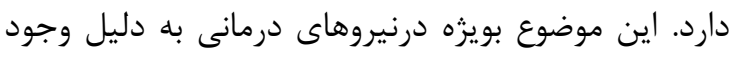

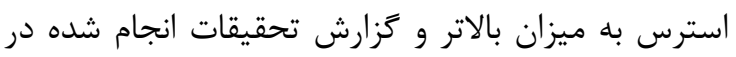

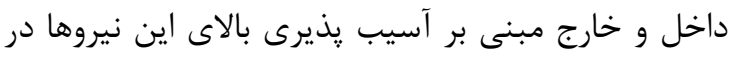

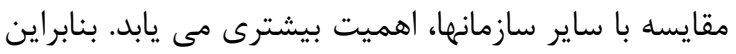

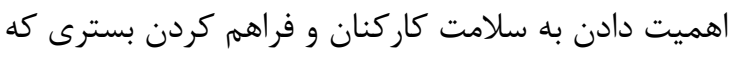

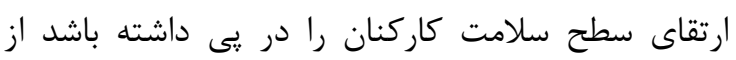
وظائف اصلى و مههم بهداشت و درمان سازمان مى بلى باشد.

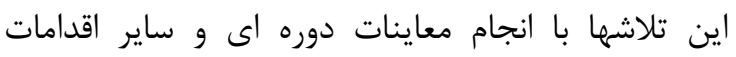

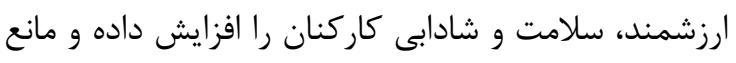

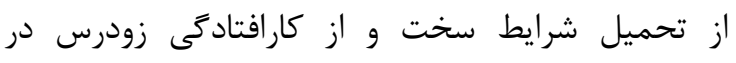

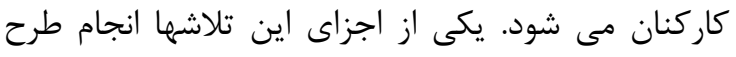

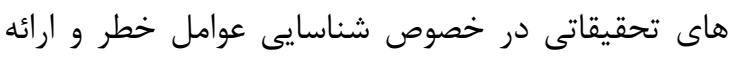

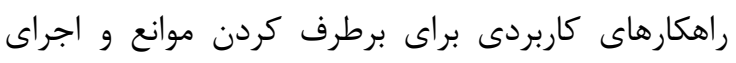

سياستهاى تامين و ارتقاى سلامت كاركنان مى بـ باشد.

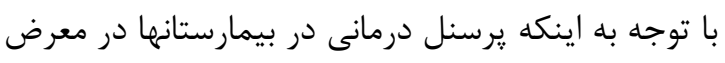

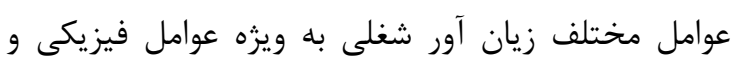

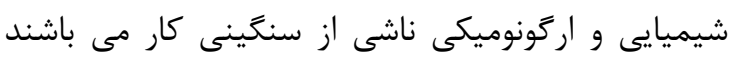

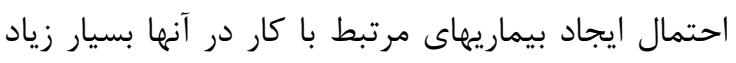

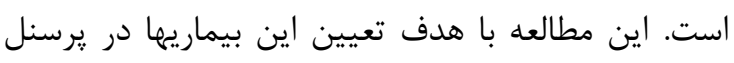

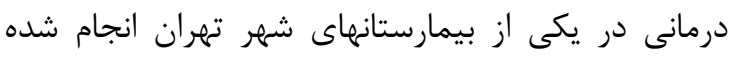

مى تواند آسيب هاى ناشى از كار و بيماريهايى مانند

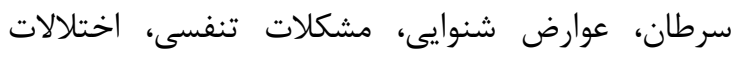
اسكلتى، عضلانى، بيماريهاى قلبى، عروقى، مشكلات تولئ، تُوليد

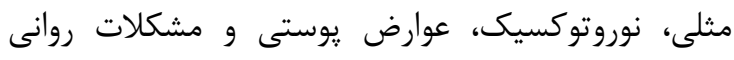

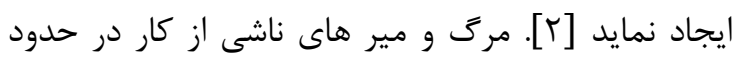

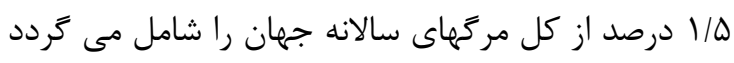

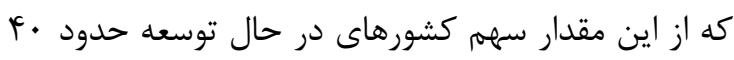

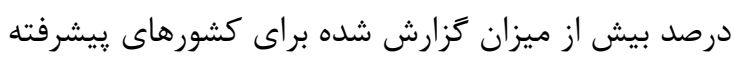

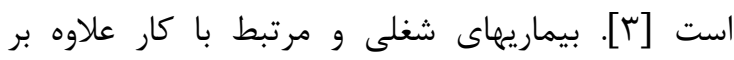
خسارتهاى آشكار از طريق حذف نيمان نيروى كار، ايجاد

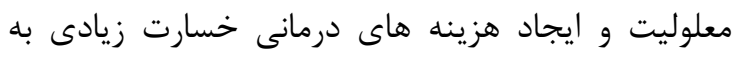

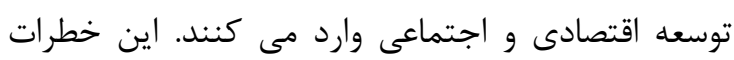

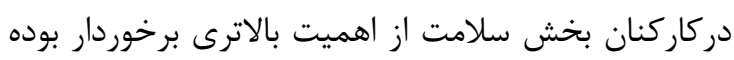

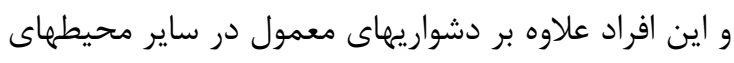

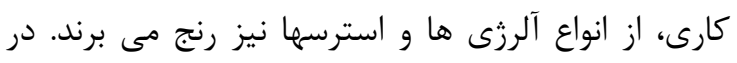

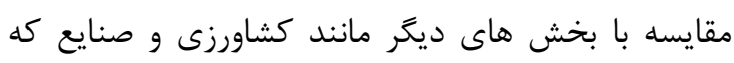

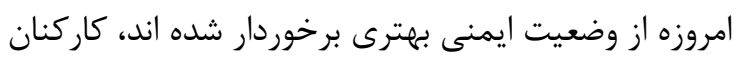
بخش سلامت در معرض ريسك هاى جدى قرار دار دارند

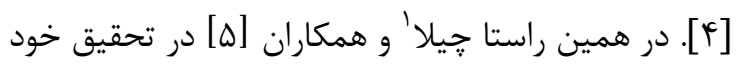

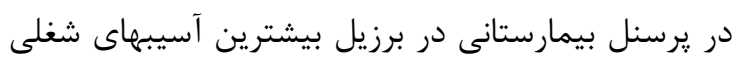

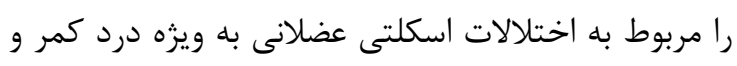

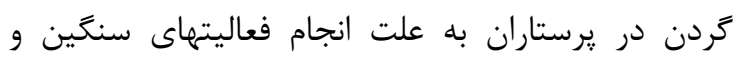

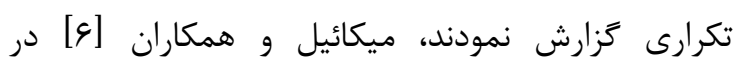

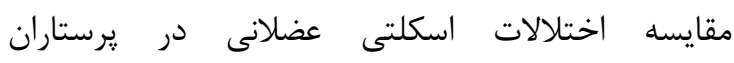

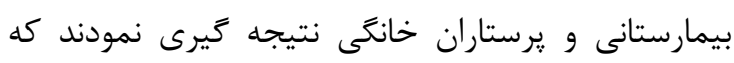

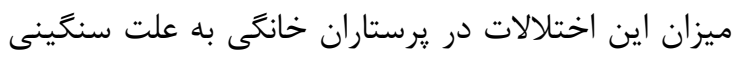

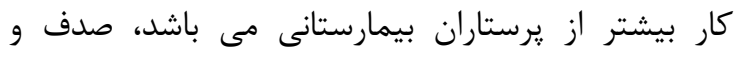

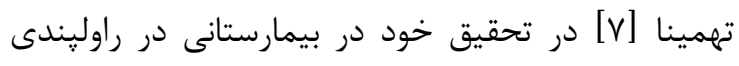

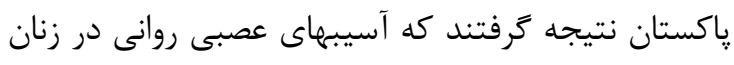

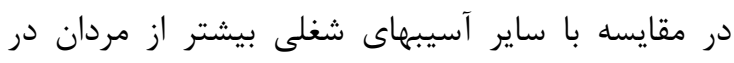

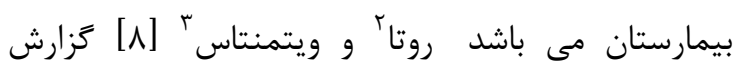

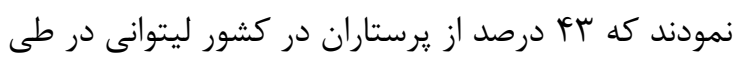
كار خود دجار عوارش يوستى شده اند كه علت اصلى آنى آنها

1 -Cheila

2- Ruta

3-Vidmantas 
آورى داده ها اقدام كرديد. براى تأييد صحت اطلاعات مربوط به نوع بيمارى ناشى از كار اظهار شده، نمونه ها جهت معاينه به متخصص طب كار معرفى شدند و افرادى

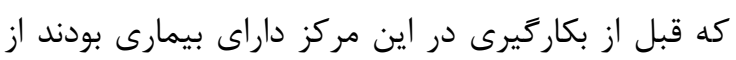
تحقيق خارج شدند و همجنين افرادى كه بيمارى آنان آندائ مربوط به كار تشخيص داده نشد به تشخيص يزشك لشاند

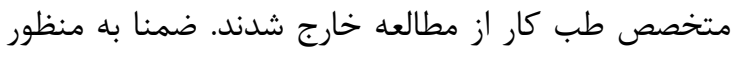

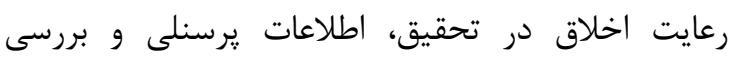
بيمارى افراد به طور كامل به صورت محرمانه انجام گرفت

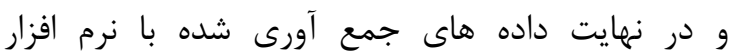
SPSS16 و آزمون هاى دآمار توصيفى و و تحليلى مانند توزيع فراوانى، تست فيشر و كاى دو مورد تجزيه و تحليل

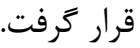

يافته ها

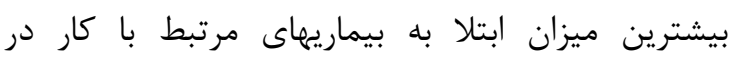

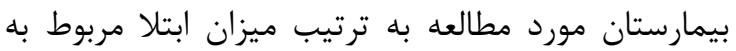
اختلالات اسكلتى عضلانى، روحى روانى، يوستى و عفونى

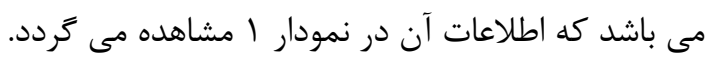

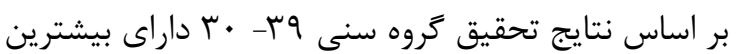

$$
\text { روش كار }
$$

اين مطالعه از نوع توصيفى- مقطعى است كه بر روى

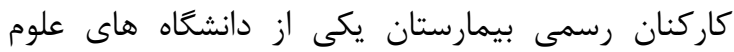

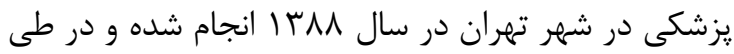

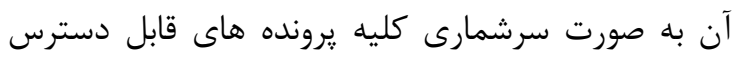

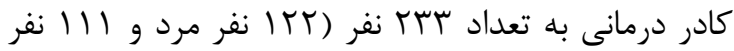

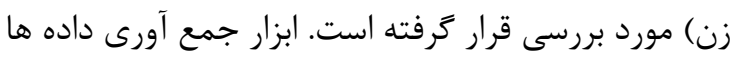

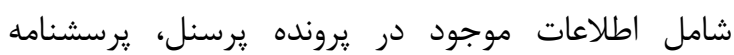
مربوط به بيماريهاى ناشى از كار بود. براى اعتبار محتواى برى بردي يرسشنامه ها از كارشناسان متخصص در زمينه هارئاي

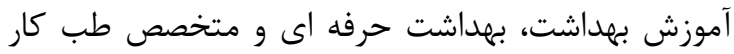

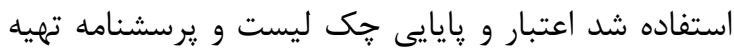
شده به ترتيب با روش هاى اعتبار محتوا

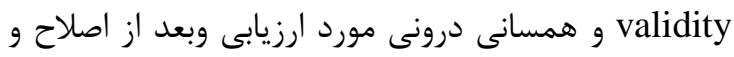

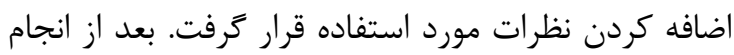
هماهنگى هاى لازم با مسئولين مربوطه در دانشخاه و شناسايى و توجيه همكاران زرسشكر، مطابق با برنامه تنظيمى و فرمهاى مربوط به شكل حضورى به نمونه هاى

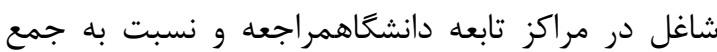

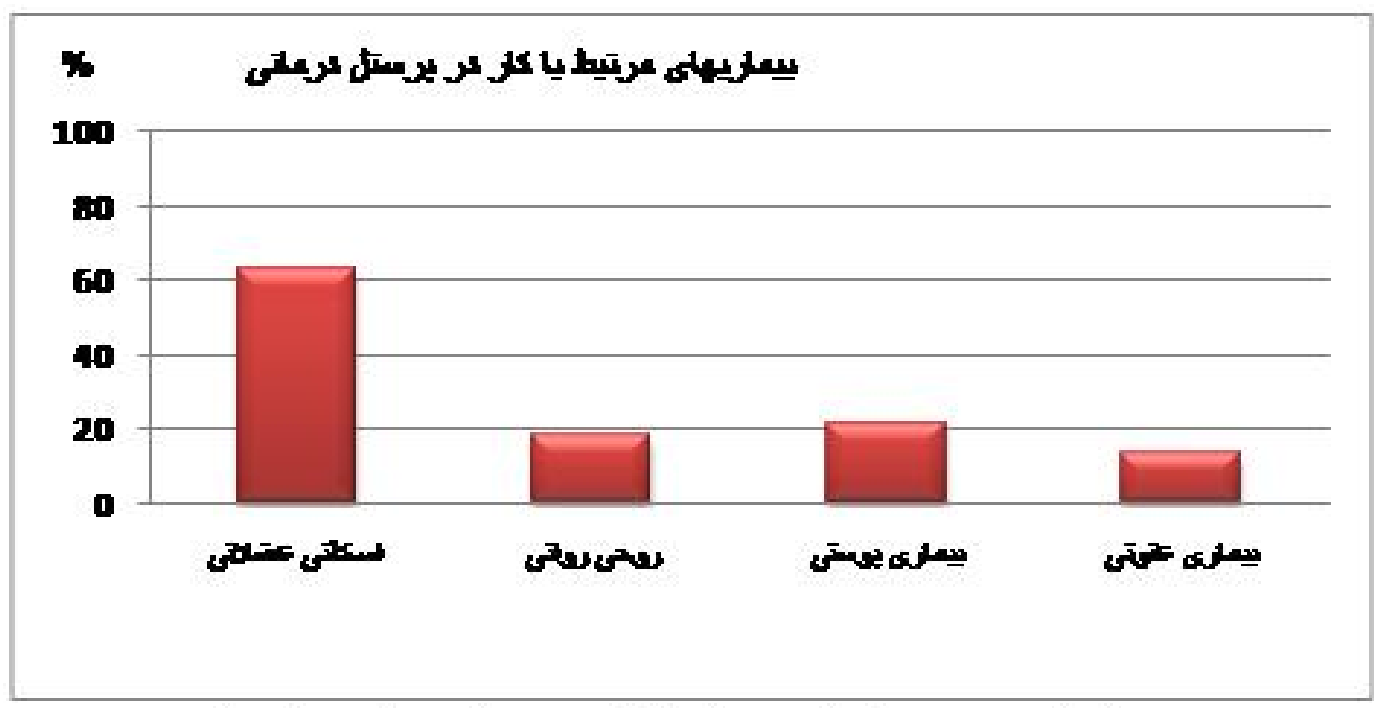

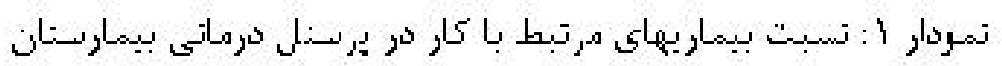


جدول ا: توزيع فراوانى مطلق ونسبى بيمارى اسكلتى عضلانى در كاركنان يكى از بيمارستانهاى شهر تهران برحسب متغيرهاى سن، جنس، شغل و سابقه كار

\begin{tabular}{|c|c|c|c|c|}
\hline \multirow{2}{*}{ جمع } & ن ندارد & دارد & \multicolumn{2}{|c|}{ بيمارى اسكلتى عضلانى } \\
\hline & تعداد(درصد) & تعداد(درصد) & & \\
\hline (1) & $(F / / F) \mid r$ & $(\Delta \wedge / \varepsilon)) \vee$ & 59 & \\
\hline$(1 \cdots) 11 \mathrm{~V}$ & $(r \Delta) F_{1}$ & $(\varepsilon \Delta) \vee \varepsilon$ & $r \cdot-r q$ & \\
\hline$(1 \cdots) \wedge \vee$ & $(r q / 1) \mu r$ & $(\varphi \cdot / 9) \Delta r$ & $\geq r$. & 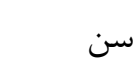 \\
\hline אשז(· (1) & $(\Gamma V / \Gamma) \wedge \vee$ & $(\varepsilon T / V) \mid F G$ & جمع & \\
\hline$(1 \cdot \cdots) \mid r T$ & $\left({ }^{c} \Delta / /\right) \Delta \Delta$ & $(\Delta \mathcal{F} / q) \& V$ & مرد & \\
\hline$(1 \cdots) 111$ & $(T N / \Lambda) T^{\prime}$ & $(V / / T) \vee q$ & 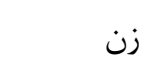 & جنس \\
\hline זسז(• •(1) & $(\Gamma V / \Gamma) V \Lambda$ & $(G T / V) \mid \& G$ & جمع & \\
\hline$(1 \cdot \cdot) \mu \cdot$ & $(\varphi \cdot) \backslash \Lambda$ & $(q \cdot) \| r$ & 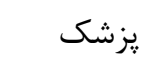 & \\
\hline$(1 \cdots) \mid F \Delta$ & $(\Gamma \Delta / \Gamma) \Delta \mid$ & $(\varepsilon q / \Lambda) q q$ & يرستار & \\
\hline$(1 \cdots) \Delta \Lambda$ & $\left(\Gamma^{\prime}\right) \backslash \Lambda$ & $(99)^{r}$. & ِيرايزشك & 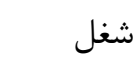 \\
\hline זrזr( (1) & $(\Gamma V / \Gamma) \wedge \vee$ & $(G T / V) \mid F G$ & جمع & \\
\hline$(1 \cdots) \mathrm{VV}$ & 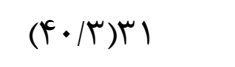 & $(\Delta q / V) \notin \varepsilon$ & $s$. & \\
\hline$(1 \cdots) \backslash \Delta \varphi$ & $(\Gamma \Delta / q) \Delta \varphi$ & $(\varepsilon+/ 1)) \ldots$ & $>1$ & سابقه كار \\
\hline מזr(• (1) & $(T V / T) \wedge V$ & $(G Y / V) \mid F G$ & جمع & \\
\hline
\end{tabular}

دقيق فيشر نشان داد كه ارتباط بين سابقه كار و بيمارى

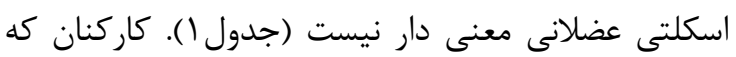

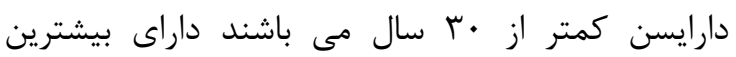

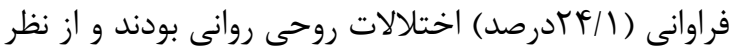

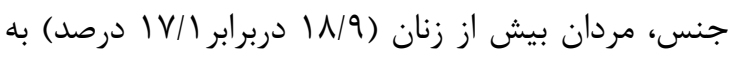

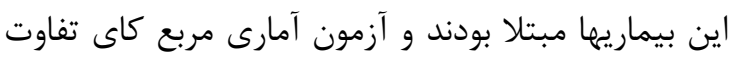

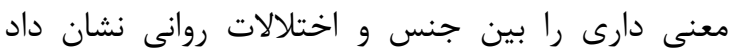

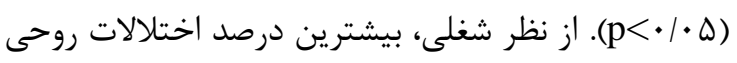

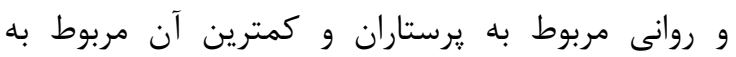

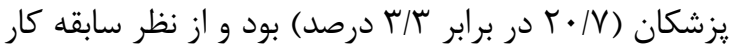

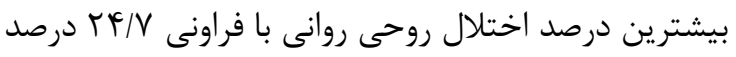

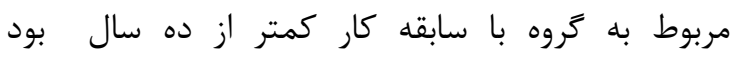

فراوانى (Q ه درصد) ابتلاء به اختلالات اسكلتى عضلانى

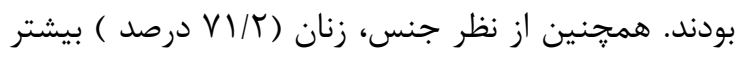

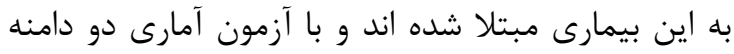
فيشر مشخص شد بين جنس و بيمارى اسكلتى عضلانى

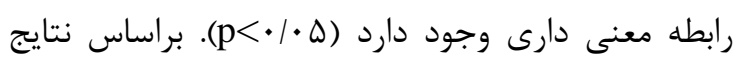

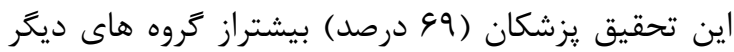

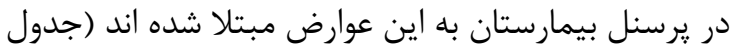

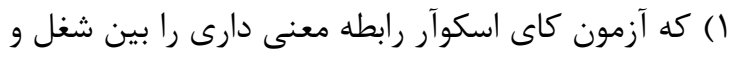

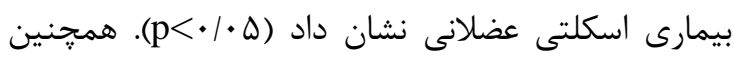
كاركنان داراى سابقه كاربيش از • إس سال بيشتر از كاركنان

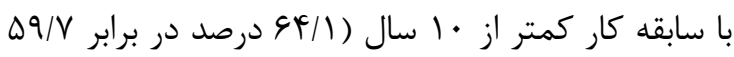
درصد) به بيمارى اسكلتى عضلانى مبتلا بوده اند. آزمون 
جدول r: توزيع فراوانى مطلق ونسبى اختلال روحى روانى در كاركنان يكى از بيمارستانهاى شهر تهران برحسب متغيرهاى سن، جنس، شغل و سابقه كار

\begin{tabular}{|c|c|c|c|c|}
\hline جمع & ن & دارد & اختلال روحى روانى & \\
\hline & & & & نوع متغير \\
\hline تعداد(درصد) & تعداد(درصد) & تعداد(درصد) & & \\
\hline$(1 \cdots) r q$ & $(V Q / Q) Y T$ & $(Y Y / I) V$ & 59 & \\
\hline$(1 \cdots) 11 V$ & $(V N / 9) q Y$ & $(r \mid / T) r \Delta$ & $r \cdot-r q$ & \\
\hline$(1 \cdots) \wedge \vee$ & $(\Lambda \wedge / \Delta) \vee \vee$ & $(\mid 1 / \Delta) \mid$. & $\geq r$. & سن \\
\hline זسז(· & $(\Lambda T) \backslash 91$ & $(1 \Lambda) F T$ & جمع & \\
\hline (1) & $(\wedge 1 / 1) 99$ & זr/ & مرد & \\
\hline$(1 \cdots) 111$ & $(\Lambda T / 9) 9 Y$ & $(1 V / 1) 19$ & 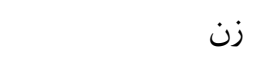 & جنس \\
\hline זسז(• • (1) & $(\Lambda T) \backslash 91$ & $(1 \Lambda) F T$ & جمع & \\
\hline$(1 \cdot \cdot) \mu \cdot$ & $(q 9 / V) r q$ & $(\Gamma / \mu) \mid$ & يزشك ي & \\
\hline$(1 \cdots) \mid \& \Delta$ & $(\vee q / \Gamma) \| Q$ & $(r \cdot / V) \Gamma \cdot$ & يرستار & \\
\hline$(1 \cdots) \Delta \Lambda$ & $(\Lambda I) \& V$ & $(19) 11$ & "ِيرايزشك & 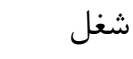 \\
\hline ח & $(\Lambda T) \backslash 91$ & $(1 \Lambda) F T$ & جمع & \\
\hline$(1 \cdots) \mathrm{VV}$ & $(\mathrm{V} \Delta / \Gamma) \Delta \Lambda$ & $(Y F / Y) 19$ & $\leq$. & \\
\hline$(1 \cdot \cdots) \mid \Delta \varphi$ & $(\Lambda \Delta / \mu) \mid r \mu$ & $(I F / V) r T$ & $>1$. & سابقه كار \\
\hline سזr( • (1) & $(\Lambda r) \backslash 91$ & $(1 \Lambda) E T$ & جمع & \\
\hline
\end{tabular}

يوستى مربوط به يزشكان و كمترين آن مربوط به

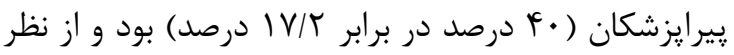

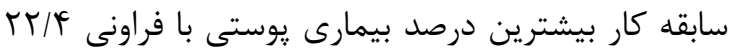

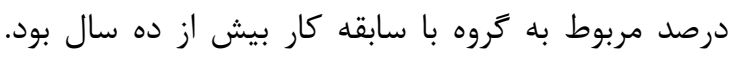

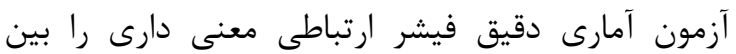
سابقه كار و بيمارى يوستى نشان نداد (جدول ارئ).
(جدول r). كاركنان كمتر از •· سال داراى بيشترين

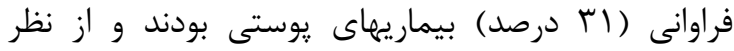

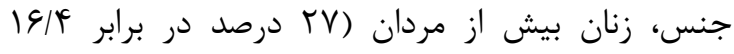

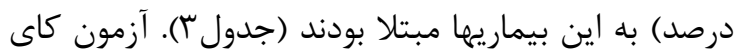

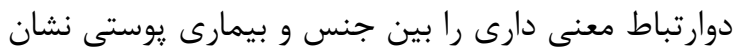

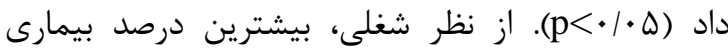


جدول ז: توزيع فراوانى مطلق ونسبى بيمارى يوستى در كاركنان يكى از بيمارستانهاى شهر تهران برحسب متغيرهاى سن، جنس، شغل و سابقه كار

\begin{tabular}{|c|c|c|c|c|}
\hline جمع & ندارد & دارد & بيمارى يوستى & \\
\hline تعداد(درصد) & تعداد(درصد) & تعداد(درصد) & & نوع متغير \\
\hline q & $(99) r$. & $\left(r_{1}\right) 9$ & 59 & \\
\hline$(1 \cdot \cdots) 11 V$ & $(\Lambda Y / 9) 9 \vee$ & $(I V / I) Y$. & $r \cdot-r q$ & \\
\hline$(1 \cdots) \wedge \vee$ & $(V \Delta / q) ৎ ৭$ & $(Y Y / I) Y I$ & $\geq r$. & سن \\
\hline אזr(· • (1) & ( & $(Y / / \Delta) \Delta$. & جمع & \\
\hline (1) & $(\Lambda r / \varphi)) \cdot r$ & $\left(\mid \varepsilon / K^{q}\right) Y$. & مرد & \\
\hline$(1 \cdots) 111$ & $\left(V^{M}\right) \wedge 1$ & $(T V) r$. & زن & جنس \\
\hline זسז(· • (1) & $(\vee \wedge / \Delta) \backslash \wedge$ & $(Y) / \Delta) \Delta \cdot$ & جمع & \\
\hline$(1 \cdots) \mu \cdot$ & $(\varphi \cdot) \backslash \Lambda$ & $(\boldsymbol{l} \cdot) \| T$ & يزشك يز & \\
\hline$(1 \cdots) \mid F \Delta$ & $(\Lambda \cdot / V) \| \vee$ & $(19 / \Gamma) Y \wedge$ & يرستار & \\
\hline$(1 \cdot \cdots) \Delta \Lambda$ & $(\Lambda T / \Lambda) \& \Lambda$ & $(\mid V / T) \mid$. & ييرايزشك & شغل \\
\hline זrז( • •1) & ( & $(Y) / \Delta) \Delta \cdot$ & جمع & \\
\hline$(1 \cdots) \mathrm{VV}$ & $(\Lambda \cdot / \Delta) \& r$ & $(19 / \Delta) \mid \Delta$ & $s$. & \\
\hline$(1 \cdot \cdots) \mid \Delta q$ & $(V V / G)|Y|$ & $\left(Y T / T^{\mathcal{C}}\right) \boldsymbol{H}_{\Delta}$ & $>1$. & سابقه كار \\
\hline سזr( • (1) & ( & $(Y) / \Delta) \Delta$. & جمع & \\
\hline
\end{tabular}

نتايج حاضر همخوانى دارد كه به نظر مى رسد علت اصلى

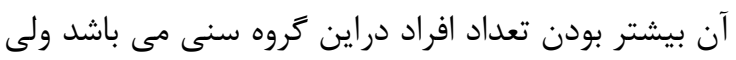

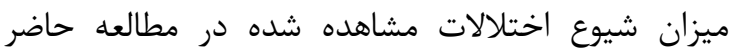

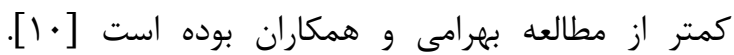
همجنين مطالعه رحيمى و همكاران در بررسى شيوع دردهاى ستون فقرات در يرستاران شاغل در بيمارستان

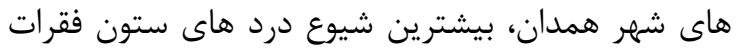

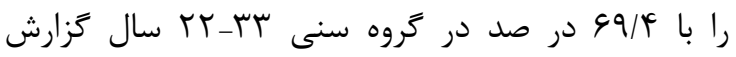

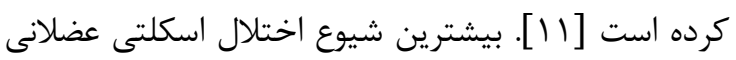

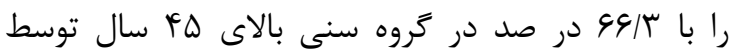
محسنى بند يى و همكاران ارائه شده است. مطالعات انجام

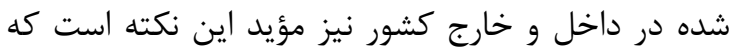

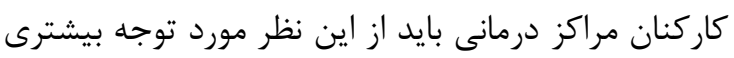

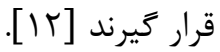

نتايج مطالعه نشان داد كه 9T/V درصد از كاركنان دجار اختلالات اسكلتى عضلانى بودند كه بيشترين فراوانى اين إن إنان

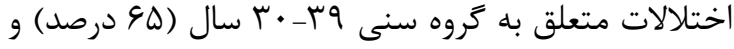

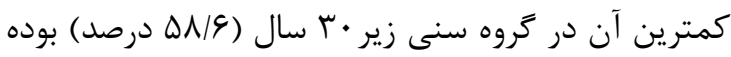

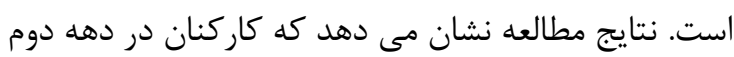
خدمتى در مراكز درمانى با مشكلات جدى مربوط بهانه اختلالات اسكلتى عضلانى مواجه مى شوند كه بر برنامه ريزى براى ريشگيرى و يا كاهش شيوع اين اختلات الاتلات

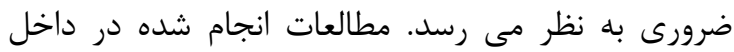
كشور از جمله مطالعه بهرامى و همكاران در بررسى

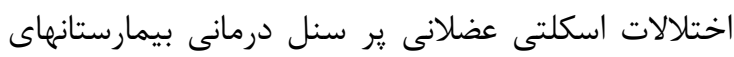
كاشان نشان مى دهد كه بيشترين فراوانى اين اختلالات برات

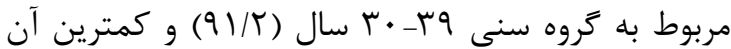

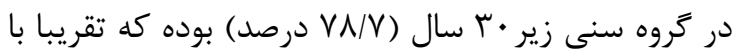


مطابقت ندارد كه به نظر مى رسد به علت كمتر تر بودن

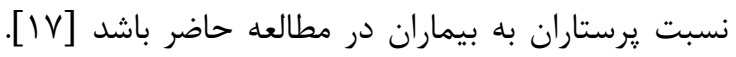

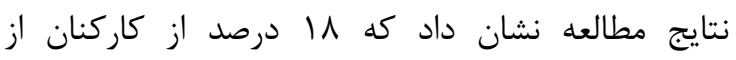

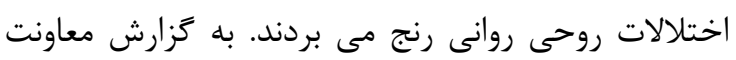

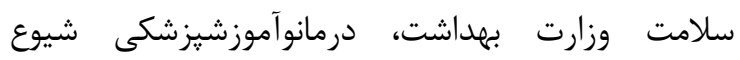

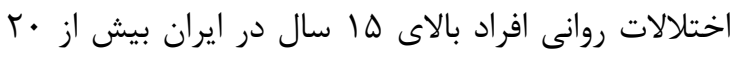

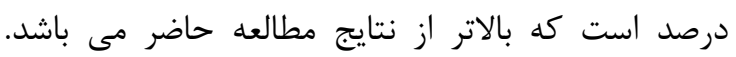

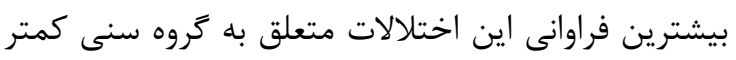

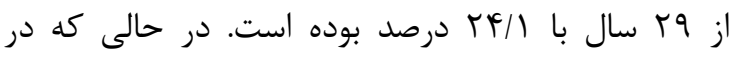

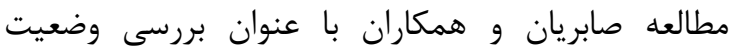

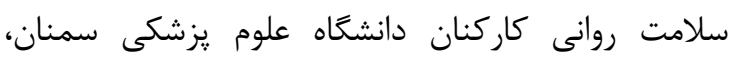

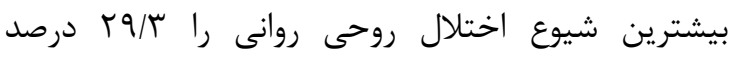

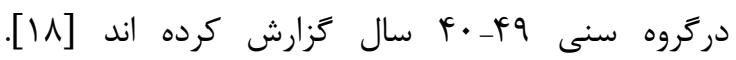

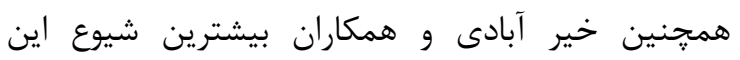

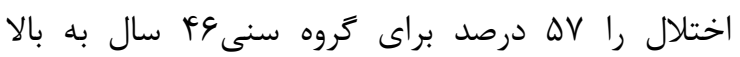

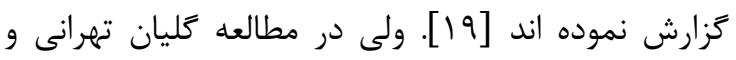
همكاران كه روى ماماهاى شاغل در تهران انجان اندام دادند

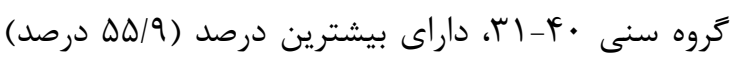

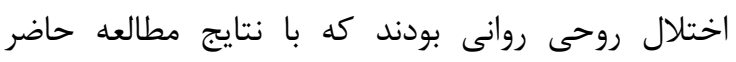
همخوانى ندارد كه به نظر مى رسد علت آن آن بالاتر بودن ماند

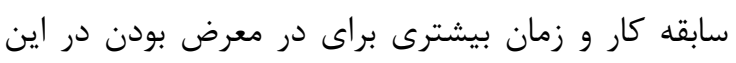

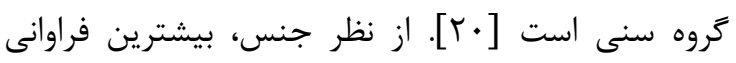

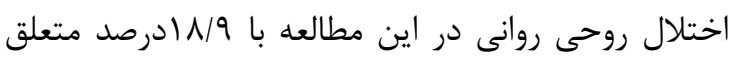

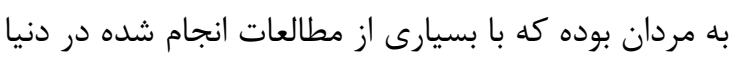

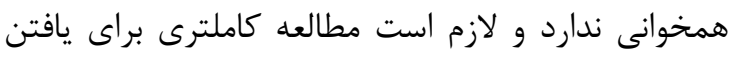

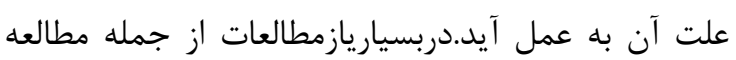

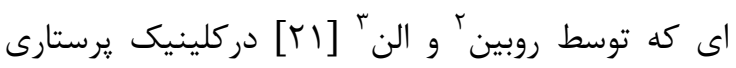

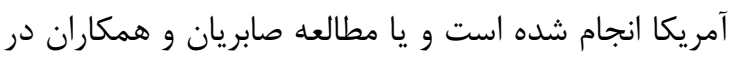

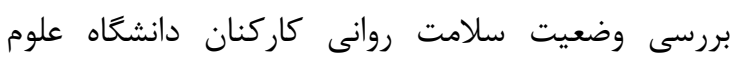

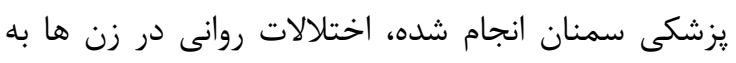

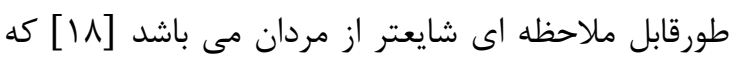

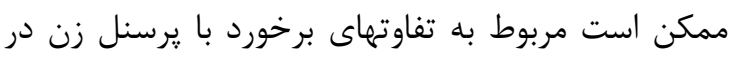

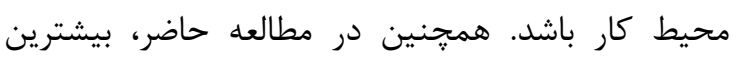

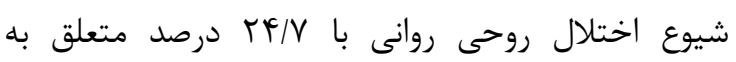

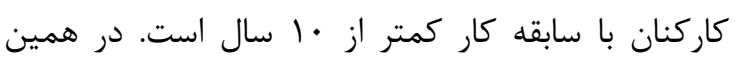

\section{2- Robynn}

3 -Ellen
در مطالعه حاضر بيشترين فراوانى نسبى اختلالات اسكلتى

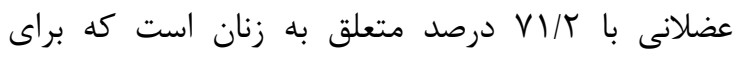

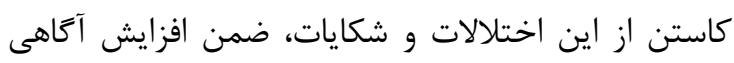

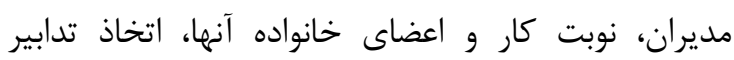

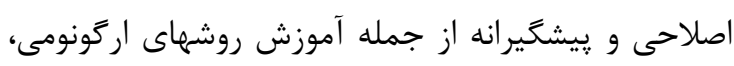
همجنين اصلاح وضعيتهاى كارى و بكار كيرى وسايل

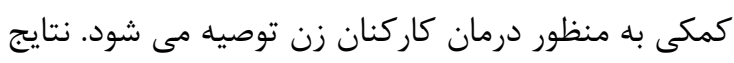

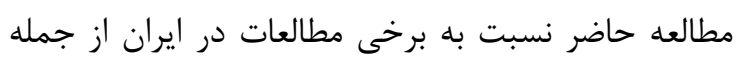

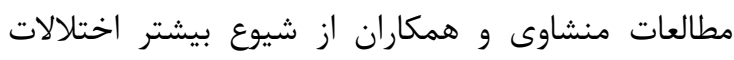

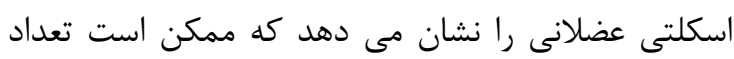

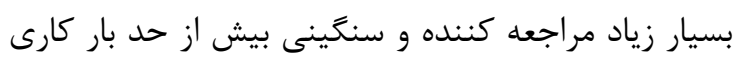

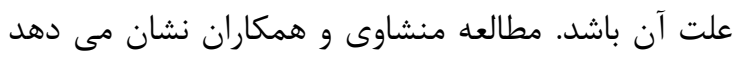

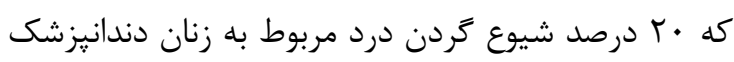

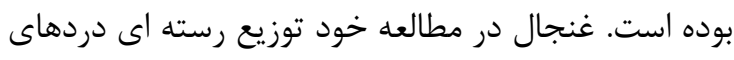

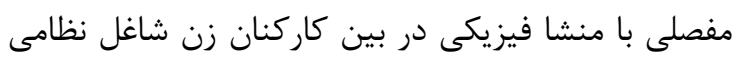

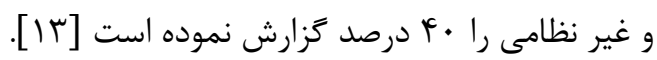

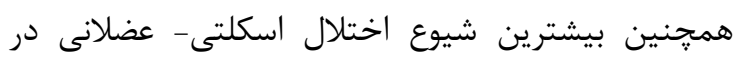

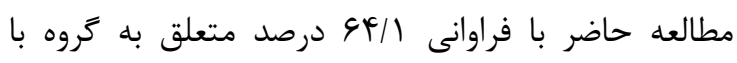

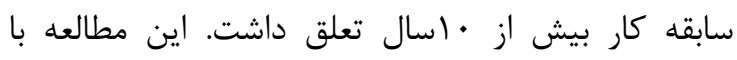

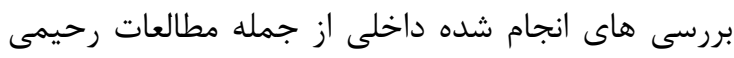

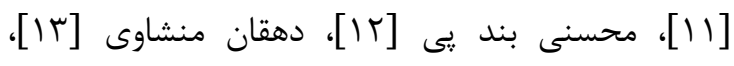

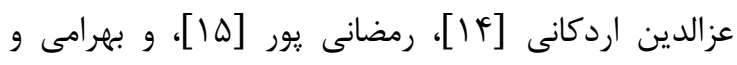
همكاران [•l] كه ارتباط معنى دارى را بـ بين مشكلات

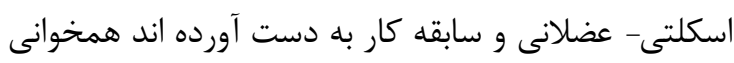

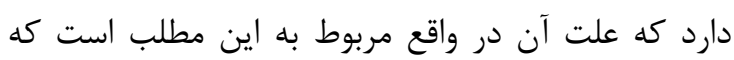

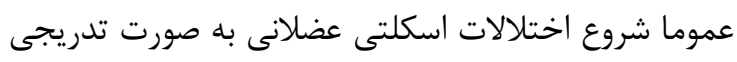

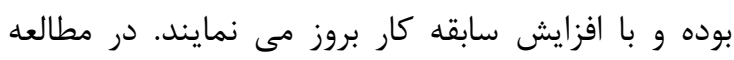

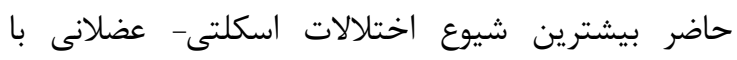

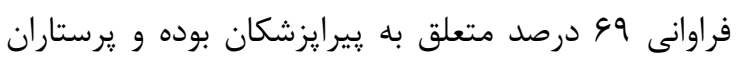

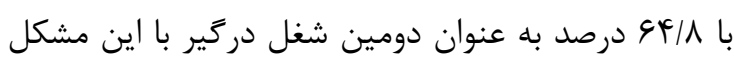

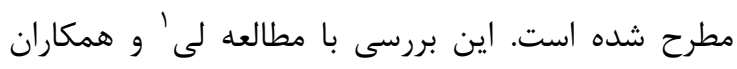

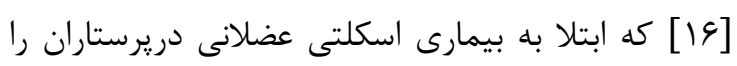

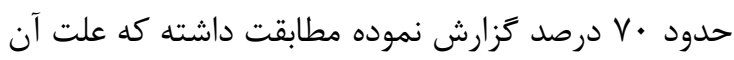

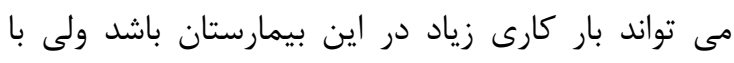

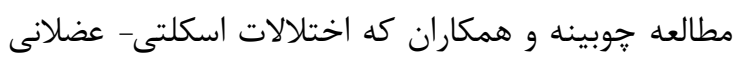

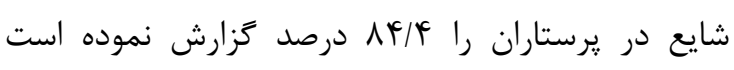

1- lee 
مى باشد [Yo[ دمر حالى كه نتايج مطالعه صادقيان و همكاران [Tr] ارتباط معنى دارى بين بيماريهاى يوستى دالى

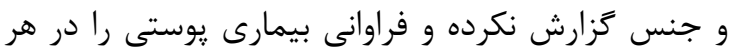

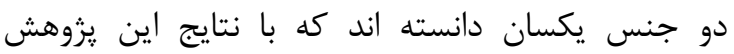
همخوانى ندارد. نتيجه كَيرى با توجه به نتايج به دست آمده از اين مطالعه، كاركنان

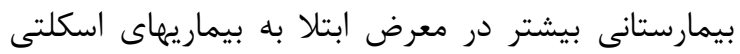

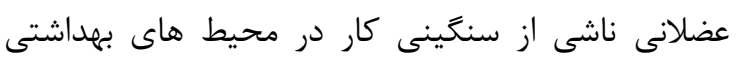

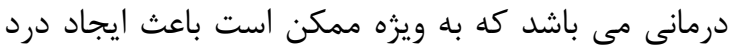

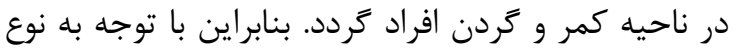

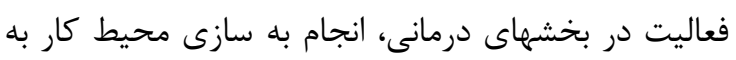

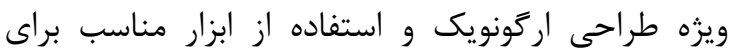

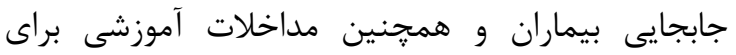

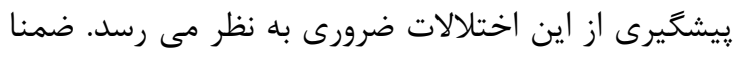

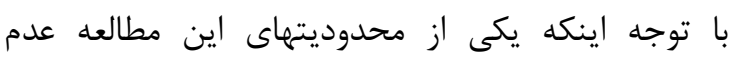

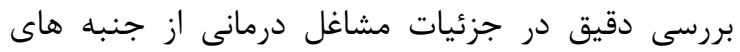

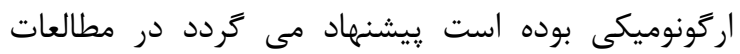

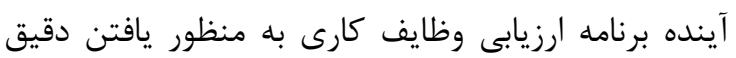

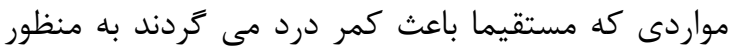
ارائه راه حلهاى فنى و اركونوميكى به عمل آيد. تشكر و قدردانى

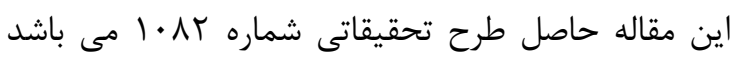

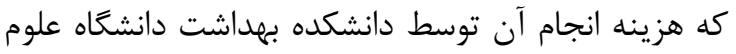
يزشكى بقيه الله (عج) يرداخت كرديده است. ضمنا از

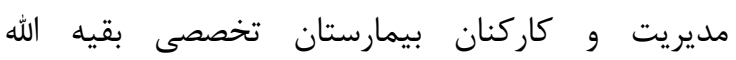
الاعظم (عج) تهران كه در انجام اين تحقيق همكارى بسيار

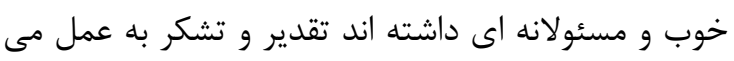

\section{References}

1. Derk SJ, Marsh SM, Jackson LL, Centers for Disease Control and Prevention (CDC), Nonfatal occupational injuries and illnesses-United States, 2004. MMWR Morb Mortal Wkly Rep.2007 Apr 7;56(16):393-7.

2. Ministry of Health and Medical Education. World Health Report 2002 First Printing, Tehran: IbnSina, the great cultural institutions; 1381. P. 111.

3. Marsh SM, Derk SJ, Jackson LL, Centers for Disease Control and Prevention (CDC),
رابطه صابريان و همكاران [1/] در مطالعه خود با عنوان بررسى وضعيت سلامت روانى كاركنان دانشخاه علوم يزشكى سمنان اين ميزان را در كاركنان با سابقه كار كمتر

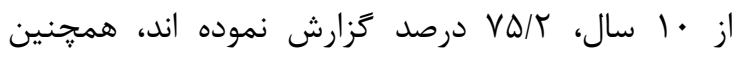

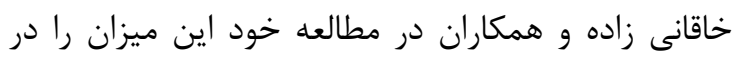

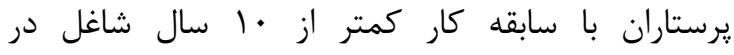

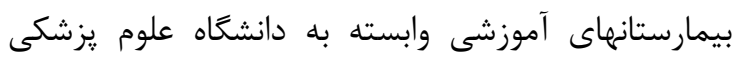

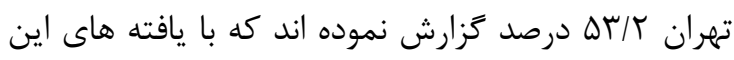

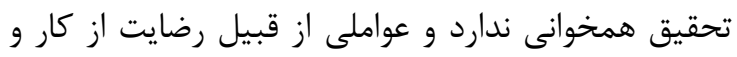

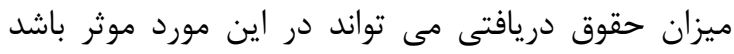

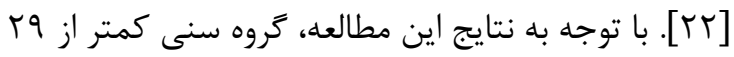

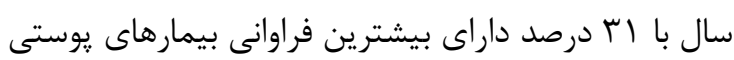
بود. در همين خصوص صادقيان و همكاران در مطالعه

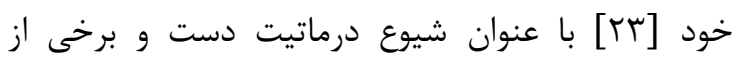

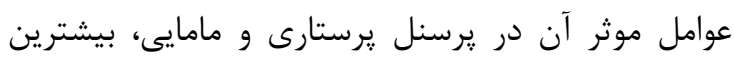

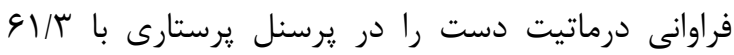

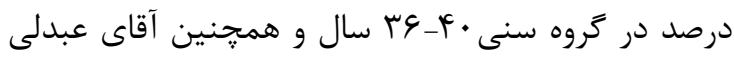

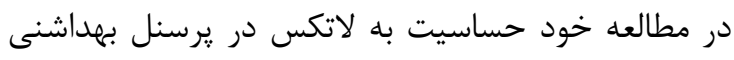

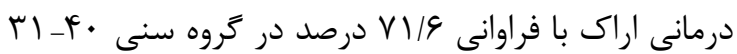
كزارش كرده اند كه با نتايج اين مطالعه همخوانى ندارد كه

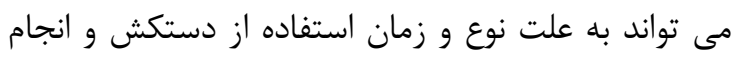

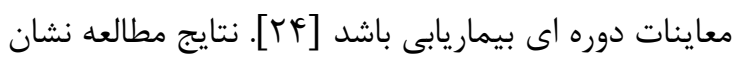

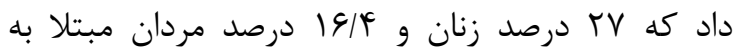
بيمارى يوستى بودند. يورياك و همكاران در مطالعه خود درد دران

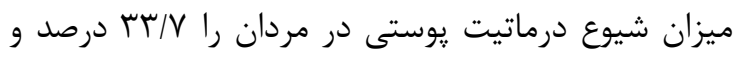

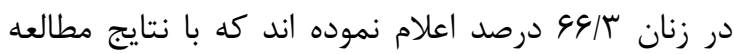
حاضر از نظر بالاتر بودن اين بيمارى در زنان همخوان دانى دانى

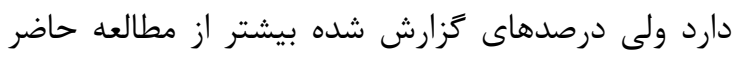

Nonfatal occupational injuries and illnesses among workers treated in hospital emergency departments--United States, 2003, MMWR Morb Mortal Wkly Rep 2006 Apr 28;55(16):449-52.

4. WHO, The world health report, Available from: www.who.int. 2005.

5. Cheila M, Maria, Fabiana C, "et al", Workrelated musculoskeletal disorders in nursing professionals: an integrative literature review, ActapaulEnferm J. 2012: 25: 48-53. 
6. Michael S, Peter T, Albert N, Back or neckpain-related disability of nursing staff in hospitals, nursing homes and home care in seven countrie, International Journal of Nursing Studies J. 2008; 45: 24-34.

7. Sadaf J, Tehmina Y, Gender Based Occupational Health Hazards among Paramedical Staff in Public Hospitals of Jhelum, International Journal of Humanities and Social Science 2011; 3: 165-169[Persian] 8. Ruta T, Vidmantas J, Occupational Skin Diseases In Nurses, International Journal of Occupational Medicine And Environmental Health 2003; 16: $241-247$.

9. Ghanjal A , Motaghi M , Sedigh N , Comparison of distribution of physically induced joints pain in military and nonmilitary patients, Journal of Military Medicine 2008; 9 (4) :283-287.

10.Bahrami A, Akbari H, Namayandeh M, Abdollahi N, Assessment of the musculoskeletal complaints of Kashan university hospitals staffs in 2006 KAUMS Journal ( FEYZ ), 2009; 12 (5) :33-38[Persian] 11.Rahimi A, Ahmadi F, Akhoond M.R, An Investigation into the Prevalence of Vertebral Column Pains among the Nurses Employed in Hamedan Hospitals, 2004 Razi Journal of Medical Sciences, 2006; 13 (51) :105114[Persian]

12.MohseniBndpy M., Fakhri, M., Ahmad Shirvani M, BagheriNesamy M, Khalilian A. Epidemiologic study of back pain in nurses.Journal of Babol University of Medical Sciences 2005; 7 (2) :35-40[Persian].

13.Dehghan Corresponding Author: Faride, AmiriZohre, RabieeMalihe, Prevalence of musculoskeletal pain among a group of Iranian dentists, (Tehran-1999) Journal of Dental School ShahidBeheshti University of Medical Sciences, 2003; 21 (2) :185-192.

14.EzoddiniArdakani F, HaerianArdakani A, AkhavanKarbasi $\mathrm{MH}$, DehghanTezerjaniKh. Assessment of musculoskeletal disorders prevalence among dentists, Journal of Dentistry, Tehran University of Medical Sciences, 2005; 17 (4) :52-60[Persian].

15.RamazaniBadr F, Nikbakht A, Mohammadpour A, Low-back pain prevalence and its risk factors in nurses Iranian Journal of Nursing Research 2006; 1 (2): 37-42[Persian].
16.LeeJH, Hoshino Y, Epidemiological comparison of low back pain in three Asiancountries, J OrthopSurg 1998; 6(2): 23 28.

17.Choobineh A, Rajaeefard AR, Neghab M, Perceived demands and musculoskeletal disorders among hospital nurses Hakim Research Journal 2007; 10 (2) :70-75.

18.Saberian M., Hajiaghajani S., Ghorbani R., Behnam B., Maddah S., The mental health status of employees in Semnan University of Medical Sciences (1385) koomesh, 2007; 8 (2) :85-92 [Persian].

19.Kheirabadi G., Yousefi F, Mental health of people over 15 years in Kurdistan province and its related factors Journal of Kurdistan University of Medical Sciences 2002; 6 (24):34-39[Persian].

20.GolyanTehraniSh, Monjamed Z, Mehran A, Hasheminasab L, Mental Health Status among Midwives Working in Tehran's Public Hospitals, Journal of Faculty of Nursing and MidwiferyTehran University of Medical Sciences (HAYAT) 2007;13(1): 7380[Persian].

21.Robynn Z, Ellen O, Women's mental health: Depression and anxiety,Philadelphia: The Nursing Clinics ofNorth America; 2009 . P 543-549.

22.khaghanizade M, Siratinir M, Abdi F, Kaviani H, Assessing of mental health level of employednurses in educational hospitals affliated to Tehran medical sciencesuniversity, The Quarterly Journal ofFundamentals of Mental Health 2006; 8 (31\& 32): 141148[Persian].

23.Sadeghian F, DelvarianZadeh M, KalalyanMoghadam H, Hosseinzadeh S, The prevalence of hand dermatitis, and some of the factors in the nursing and midwifery personnel, Daneshvar Bimonthly 2006; 14 (67): 2532[Persian].

24.Abdoli S, Sensitivity to latex in health care personnel in hospitals of Arak University of Medical Sciences 2002, Journal of Ilam University of Medical Sciences 2007; 12 (4243): 32-38.

25.Pourpak Z, \& "et al", A cross-sectional study of Latex allergy among operation room staff of hospitals of Tehran University of Medical Sciences, 1380-81.Iranian Journal of Dermatology 2004; 7(28): 219-230. 


\title{
Study of work related diseases among staff of a hospital in Tehran
}

\author{
Salem $M^{1}$, RashidiJahan $H^{2 *}$, Tavakoli $R^{3}$, Sanaienasab $H^{3}$, pourtaghi $G^{4}$, karimizarchi $A A^{5}$ \\ ${ }^{1}$ lecturer dept. of Occupational health ,School of Health, Baqiyatallah University of Medical Sciences, Tehran, \\ Iran. \\ ${ }^{2}$ lecturer dept. of Health education, School of Health, Baqiyatallah University of Medical Sciences, Tehran, Iran. \\ ${ }^{3}$ Assistant professor dept of Health education, School of Health, Baqiyatallah University of Medical Sciences, \\ Tehran, Iran. \\ ${ }^{4}$ Assistant professorHealth Research Center. Baqiyatallah University of Medical Sciences, Tehran, Iran. \\ ${ }^{5}$ Associated professor dept. of Biostatistics \& epidemiology, School of Health, Baqiyatallah University of \\ Medical Sciences, Tehran, Iran.
}

\section{*Corresponding Author: \\ School of Health, Baqiyatallah \\ University of Medical \\ Sciences, Tehran, Iran. \\ Email: hojatr73@gmail.com}

Submitted:25 May 2013

Revised:3 July 2013

Accepted:7 Sep 2013

\begin{abstract}
Background \& objectives: The use of technology has increased occupational diseases. People in work zone may be exposure to various harmful agents such as physical, chemical, ergonomic, biological and psychological agents. These factors can lead to many of occupational and work related diseases. This study aimed to determine the work related diseases among staff of a hospital in Tehran.
\end{abstract}

Material \& Methods:This descriptive cross-sectional study was conducted on 233 hospital's staff. Job records and the check list of work related diseases were used to collect data. Descriptive and analytical statistics using SPSS version 16 were applied for analysis.

Results:The results showed that $62.7 \%$ of workers had musculoskeletal disorders. These disorders were more reported among people aged 30 to 39, females, paramedics and people with more than 10 years of work history. Prevalence of mental disorders was $18 \%$ and working age group of less than 29 years had the highest frequency among them. Skin diseases related to work with a prevalence rate about $24.1 \%$ among people aged more than 40 years was considerable.

Conclusion:Work-related diseases in hospital are common especially musculoskeletal that caused by ergonomic agents. Regarding to high prevalence of work related diseases especially musculoskeletal disorders, among participants, applying educational interventions adjusted to job type of personnel could be a practical suggestion.

Key words: Work related disease, musculoskeletal disorders, hospital's staff, harmful agents 